\title{
Functionalism-Related Framework and the Influence on Language Instruction
}

\author{
Khafidhoh \\ khafidhoh@pbi.uad.ac.id \\ Universitas Ahmad Dahlan
}

\begin{abstract}
Functionalism is one of the basic ways of thinking in linguistics while the language instruction is a complex process dealing with the language use. This article aims at giving a critical review on functionalism-related function and the influence on the language instruction area. The topics covered in this article are the definitions of the general explanation of functionalism, linguistic inputs, philosophical inputs, sociolinguistic inputs, needs analysis on language instruction, and the influence of functionalism on language instruction.
\end{abstract}

Keywords: functionalism, influence, language instruction

\section{A. Introduction}

Functionalism is one of the two basic schools of thought in linguistics. Richards and Schmidt (2001: 214) define the word 'function' as the root of the word 'functionalism' as the purpose for which an utterance or unit of language is used. In accordance with the definition, especially in language instruction, the language functions are often described as the categories of behavior such as requesting, agreeing something, and so on. Then, because of the complicated unit of the language function, it cannot be determined by simply studying the grammatical features, it should be analyzed deeper. Moreover, the meaning or the functions are based on the situation or so called the mood of the producer and the receiver. Based on the explanation, the writer tries to elaborate the term functionalism. In conclusion, functionalism is a way of thinking in which the linguists deal with not only the unit of the language but itself but also the other factors related to the use of the language units such as the psychological, social, and situational factors.

\section{B. Linguistic Inputs}

Richards and Schmidt (2002: 214) give the example of various functions of a similar pattern of language unit which is imperatives as follow.

1. Give me that book. (imperative functions order)

2. Pass the jam. (imperative functions as request)

3. Turn right at the corner. (imperative functions as instruction)

4. Try the smoked salmon. (imperative functions as suggestion)

Based on those differences, we should consider three key problems which have important implications for linguistic inputs as well as applied linguistics. Bell (1981: 197) proposes the three keys of problems for linguists: 
1. The place of semantics in grammar

The motivation for this arose mainly from transformation- generative definition of language as a system of meanings. However, it was not until the mid 1960s that transformation - generative turned its attention to the study of semantics. That is a change of orientation which led almost immediately to a split among transformationalism on the place and status of semantics within the grammar.

Then, Clarck \& Clarck (1977: 437) propose that concepts are defined by rules within the functional approach. There is an assumption that people actually decide whether or not an object belongs to a category. This assumption has been made concrete in the approach called procedural semantics. It is the sense of a word applies to a thing. The procedure is written as they were a computer program with a series of steps. The procedures are more general. One criticism of semantic components is that not all words can be defined in terms of necessary conditions.

Next, language is not always meant as the literal meanings of each language unit. The meaning can be different based on the word formation and even other part of the language. Clark \& Clark (1977: 444) states that it is incorrect if each word is treated as if it had one and only one sense. There are some reasons why the meaning is not always the same. He explains more that it is because three reasons.

a. Polysemy

Polysemy means the words which have more than one sense. The examples are as follow.

1) The visible organ of hearing, as in floppy ears. (sense one)

2) The sense of hearing, as in good ear for jazz. (sense two)

3) The spike that bears corn, as in three ears of corn. (sense three)

All of the words "ear" are homonyms because they have the same form but they have different meaning. And it also happens to the other words. They might have different form and meaning.

b. Idiom

Idioms are phrases with social meanings. The phrase kick the dog has the sense from "kick" (Strike with one's foot) and "dog" ("canine animal") and it means "Strike the canine animal with one's foot". But the real meaning of this idiom is "die". It is just the same as other idioms such as hit the sack, put one's foot in one's mount, or be in hot water.

c. Lexical Creativity

Language users invent new uses for old words and sometimes invent new words altogether. This happens when the language leaves them too little room to maneuver efficiently. This mountain is jeepable, The player had to be stretchered off the field and The rocket faltered at lift-off. The interesting parts are the words jeepable, stratchered, and lift-off. The mental lexicon does 
not contain them ready-made in this form. However, they are created on the spot as a normal part of speaking and listening.

2. The relationship of variation to the model

Some variation is clearly not dialectal at all but "stylistic "depending on the use to which the language is being put by the users. In language instruction, some rough distinction between " formal and informal", " speech and writing" and some kinds of specification of the regional and social dialect have always been recognize as essential for the definition of the precise variety of the code at which the learner is expected to aim. From this grew substantial work on register which showed how different varieties of a language were product of the situational constraint under which they were used such as addressee relationship, purpose, time, place, etc. A register was seen as a kind of sublanguage or limited language indeed the whole language was thought of as made up of a collection of registers which was described by correlating the linguistics forms in appropriate texts with situational variables.

3. The problem of the function of language

Language functions are related to the question of "what is language for?". The answer of this question trying to describe in any definition below.

a. First of all, language conveys ideas. It means language has a cognitive function, focusing on the context in which the message is transmitted, referring to objects and concepts.

b. Secondly, language has an ability to convey information about the speaker such as his age, sex, social class, level of education, his attitude to the topic and to the other participants. This function has been termed indexical and is far less under the conscious control of the speaker than is the cognitive information transmits.

c. Thirdly, language conveys our participation in the process of communication. By this we mean that language is used to refer to the interaction the point that has been reached, our desire to gain or concede the floor or our willingness to bring the conversation to a close.

d.

\section{Philosophical Inputs}

Some philosophers are seriously concerned with the explanation of the ordinary language which brought their own interest closer to those of the linguist and form the mid-1950s moved away from purely referential uses of language to the study of the social uses to which language is put; an interest which relates closely to that of sociolinguistics. Bell (1981: 92) states that each speech act is thought of as consisting of two elements. The first element is the propositional content which is being referred to what is about. The second element is the illocutionary force which means the act intended to convey or the emphasis given to it by the speaker. Thus, the use of the language produced by the speakers or writers must be interpreted by the listeners or the readers philosophically. 


\section{Sociolinguistic Inputs}

The fact that communicators involved are distinct individuals who can rarely be certain that they share meanings and the fact that face- to- face communication takes place in a social context which permits conflicting messages to be transmitted and received through the range of channels in use, consider the way the actual words can have their meanings reversed by a change in intonation or gesture or facial expression, makes the 'noise "which occurs severe and complex. The sender and the receiver are both sources of "noise", so are the various channels and so is the social contexts in which the message is being sent and received. Thus, we need more sophisticated model which recognizes the two-way nature of human communication that speakers become hearers and that hearers provide feedback and the paramount importance of the situational constraint under which communicator operates.

\section{E. Needs Analysis on Language Instruction}

Language instruction which has some complicated elements on it should be designed based on target needs and learner needs. If we refer to the term of functionalism stated by Kridalaksana (2008: 68) who explains that functionalism is linguistics movements which assume that the phonological, semantic, grammatical and semantic structures based on the function existed in the society, the learners should learn not only the language itself but also the functions and its uses in the target situation.

\section{F. The Influence of Functionalism on Language Instruction}

The language learners are the parts of the society and there are various target situations which should be entered by the learners in their daily life. It means, the learners, finally, have to use the appropriate language functions to interact with the other people in various situations. Thus, the language instruction should facilitate them to communicate in any target situations well. In accordance with the explanation, it is important for the teachers as the instructional facilitators, researchers, as well as the curriculum developers to design the curriculum and the other instructional-related tools well by integrating the theory and the use of functions on the language instruction. The concrete framework may be the use of functional syllabus and also functionalnotional syllabus.

Functional-notional syllabus focuses on the functions as the organizing elements of English language curriculum and its contrast with a structural syllabus in which sequenced grammatical structures served as the organizers (Brown, 2001: 32). This method focuses on the pragmatic purposes to which we put the language. The term notional is defined by Van Ek and Alexander (1975) in Brown (2001: 32) as both general and specific concepts in which the language used to express thought and feeling. According to Brown (2001: 33), the use of functional-notional syllabuss are covered in the first several lessons of an advance beginner's textbook which are introducing self amd other people, exchanging personal information, asking how to 
spell someone's name, giving commands, apologizing and thinking, identifying and describing people, and asking for information.

Moreover, Brown (2001: 33) explains that the use of communicative competence implaies a set of strategies for getting messages sent and received and for negotiating meaning as an interactive participant in discourse. The language users should not only imply the meaning of the message directly by trashing the grammar but finding the best message in discourse level. Related to that theory, Indonesia has applied the use of fuctionalism in education especially for the teaching and learning processes. Then, the government has also proposed curriculum and the applications based on that way of thinking. In fact, the language instructions accommodate the use of functional senses of the language and the focus of the teching and learning processes is on building the students' ability to communicate in discourse level.

\section{Reference}

Bell, T. R. 1981. An Introduction to Applied Linguisttics: Approached and Methods in Language Teaching. Great Britain: Batsford Academic and Education Ltd

Brown, H. Douglas. 2001. Teaching by Principles: An Interactive Approach in Language Pedagogy. New York: Addison Wesley Longman Inc.

Clark, H. H., Clark E. V. 1977. Phychology and Language: An Introduction to Psycholinguistics. USA: Harcourt Brace Jovanovich Publishers.

Kridalaksana, Harimurti. 2008. Kamus Lingustik. Jakarta: PT Gramedia Pustaka Utama.

Richards, J. C., Schmidt, R. 2002. Longman Dictionary of Language Teaching and Applied Linguistics. Edinburgh: Pearson Education Limited. 